STUDI

FRANCESI

\section{Studi Francesi}

Rivista quadrimestrale fondata da Franco Simone

165 (LV | III) | 2011

LA RAPPRESENTAZIONE DELLA MADRE NELLA

LETTERATURA FRANCESE DEL NOVECENTO a cura di Dario Cecchetti e Michele Mastroianni

\title{
Henri Béhar, Ondes de choc. Nouveaux essais sur l'avant-garde
}

\section{Marcella Biserni}

\section{(2) OpenEdition \\ Journals}

\section{Edizione digitale}

URL: http://journals.openedition.org/studifrancesi/5118

DOI: $10.4000 /$ studifrancesi.5118

ISSN: 2421-5856

\section{Editore}

Rosenberg \& Sellier

\section{Edizione cartacea}

Data di pubblicazione: 1 décembre 2011

Paginazione: 670-671

ISSN: 0039-2944

Notizia bibliografica digitale

Marcella Biserni, «Henri Béhar, Ondes de choc. Nouveaux essais sur l'avant-garde», Studi Francesi [Online], 165 (LV | III) | 2011, online dal 30 novembre 2015, consultato il 13 janvier 2021. URL: http://

journals.openedition.org/studifrancesi/5118; DOl: https://doi.org/10.4000/studifrancesi.5118

Questo documento è stato generato automaticamente il 13 janvier 2021.

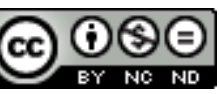

Studi Francesi è distribuita con Licenza Creative Commons Attribuzione - Non commerciale - Non opere derivate 4.0 Internazionale. 


\title{
Henri Béhar, Ondes de choc. Nouveaux essais sur l'avant-garde
}

\author{
Marcella Biserni
}

\section{NOTIZIA}

HENRI BÉHAR, Ondes de choc. Nouveaux essais sur l'avant-garde, Lausanne, L'Age d'Homme, 2010 («Bibliothèque Mélusine»), pp. 343.

1 Le «ondes de choc» emanate dalle Avanguardie, ormai dette "storiche", hanno creato un "movimento" teorico di rivoluzione del pensiero a livello globale. Queste onde magnetiche e "sinusoidali", che richiamano alla memoria quelle degli Champs magnétiques di Breton e Soupault, si sono diffuse come un sisma, tanto che lo squarcio provocato nel terreno artistico (in tutti i suoi strati) è percepibile ancora oggi. L'insieme della presente raccolta, preceduto da un ampio "prologo", è composta da una scelta di interventi e di saggi, pubblicati in rivista, nell'arco di dieci anni.

2 Henri Béhar focalizza la sua analisi su tre punti cardine, che costituirono il percorso dei gruppi d'avanguardia: la rottura, la creazione di una comunità e la volontà politica, raccontandoci un pezzo del nostro passato, l'"impasto" da cui, forse, discendiamo. Le sue riflessioni si dividono in tre sezioni e tra le informazioni di carattere storico e oggettivo scivolano alcuni dei suoi ricordi relativi agli incontri con i protagonisti.

La prima parte, dal titolo La Bombe Dada, ripercorre il ruolo che ebbe Tzara nella diffusione del Futurismo, attraverso la corrispondenza che intercorse tra il giovane poeta romeno e il côté italiano, in particolare con De Chirico, con suo fratello Savinio e con Marinetti. L'autore getta luce su temi a volte messi in ombra, come la scoperta della poesia negra, intrisa di suoni nuovi e di sinestesie, che spinse Tzara ad assaporare il gusto dell'interdisciplinarità. Béhar mette poi in evidenza il legame con Hans Arp che fu determinante in tutte le fasi del Dadaismo e l'importanza di alcuni elementi costituitivi del gruppo stesso: l'aspetto politico, rivoluzionario ma non belligerante, o la scoperta dell'inconscio. 
La sezione Lames de fond spectaculaires, continuando con la metafora del titolo, prosegue l'analisi delle forti onde di fondo, e quindi forse inconsapevoli, che investirono le Avanguardie, mostrandone le ripercussioni o gli esiti sui diversi piani. L'autore si sofferma sulla questione delle rappresentazioni dei testi shakespeariani e della fondazione del Théâtre Alfred-Jarry, sull'irruzione, esplosiva, del riso in Artaud, per poi passare alle sceneggiature surrealiste di Sylvain Itkine e alla fondazione della compagnia Le diable écarlate, fino a riportare in superficie il lavoro di Roger Vitrac nel cinema, nonché l'elevazione della provocazione a categoria drammaturgica.

5 Béhar, nell'ultima parte, utilizza per analogia la cintura di fuoco del Pacifico (dove si concentra il maggior numero di terremoti del mondo) per sottolineare i numerosi lati oscuri che, come in questi fenomeni geologici, permangono nelle avanguardie letterarie. La Ceinture de feu surréaliste individua il suo "epicentro" in figure o momenti che secondo l'autore scossero le fondamenta e i «paysages surréalistes»: la relazione Paulhan-Breton, il rapporto con il Grand Jeu, la critica letteraria su rivista, la rilevanza di Dalí e dei termini “scatologia" ed "escatologia" presenti nei suoi testi, i legami politici della corrente surrealista e il suo contributo alla creazione del Manifeste des 121. 